\title{
Local prostate cancer radiotherapy after prostate-specific antigen progression during primary hormonal therapy
}

\author{
Michael Pinkawa ${ }^{1 *}$, Marc D Piroth ${ }^{1}$, Richard Holy ${ }^{1}$, Victoria Djukic ${ }^{1}$, Jens Klotz ${ }^{1}$, David Pfister²,
} Axel Heidenreich ${ }^{2}$ and Michael J Eble ${ }^{1}$

\begin{abstract}
Background: The outcome of patients after radiotherapy (RT) for localized prostate cancer in case of prostate-specific antigen (PSA) progression during primary hormonal therapy (HT) is not well known.

Methods: A group of 27 patients presenting with PSA progression during primary HT for local prostate cancer RT was identified among patients who were treated in the years 2000-2004 either using external-beam RT (EBRT; 70.2Gy; $n=261$ ) or Ir-192 brachytherapy as a boost to EBRT (HDR-BT; 18Gy + 50.4Gy; $n=71$ ). The median follow-up period after RT was 68 months.

Results: Median biochemical recurrence free (BRFS), disease specific (DSS) and overall survival (OS) for patients with PSA progression during primary HT was found to be only 21, 54 and 53 months, respectively, with a 6-year BRFS, DSS and OS of 19\%, $41 \%$ and $26 \%$. There were no significant differences between different RT concepts (6-year OS of 27\% after EBRT and $20 \%$ after EBRT with HDR-BT).

Considering all 332 patients in multivariate Cox regression analysis, PSA progression during initial HT, Gleason score $>6$ and patient age were found to be predictive for lower OS $(p<0.001)$. The highest hazard ratio resulted for PSA progression during initial HT (7.2 in comparison to patients without PSA progression during primary HT). PSA progression and a nadir $>0.5 \mathrm{ng} / \mathrm{ml}$ during initial HT were both significant risk factors for biochemical recurrence.
\end{abstract}

Conclusions: An unfavourable prognosis after PSA progression during initial HT needs to be considered in the decision process before local prostate radiotherapy. Results from other centres are needed to validate our findings.

Keywords: Prostate cancer, Radiotherapy, Brachytherapy, Ir-192, Prostate-specific antigen, Hormone therapy

\section{Background}

External beam radiotherapy (EBRT) and temporary interstitial brachytherapy (HDR-BT) are all well established radiotherapy (RT) techniques for a curative treatment of localized prostate cancer [1-7]. The combination with hormonal therapy (HT) has been shown to be associated with improved overall survival for high risk patients after EBRT in several prospective randomized studies [8-12]. HT is frequently administered before brachytherapy for downsizing the prostate volume [13].

\footnotetext{
*Correspondence: mpinkawa@ukaachen.de

'Department of Radiation Oncology, RWTH Aachen University,

Pauwelsstrasse 30, 52072 Aachen, Germany

Full list of author information is available at the end of the article
}

The optimal sequencing and duration of HT in combination with EBRT is not well known. A longer duration of HT proved to be associated with an overall survival benefit for high risk patients in randomized trials addressing this question $[9,10,14]$. A difference was even found for a neoadjuvant HT comparing eight versus three months [14].

In daily practice, patients sometimes do not receive a well defined short-term neoadjuvant HT before presenting in the radiotherapy department. In some cases, definitive curative treatment is only postponed. Patients sometimes receive HT until PSA levels rise after an initial PSA nadir. These patients were in focus of this analysis.

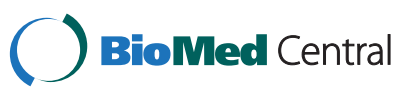


Patients after EBRT alone and EBRT with an additional HDR-BT boost have been included in this evaluation to verify the results independently in two separate patient groups with different radiotherapy concepts. Randomized trials comparing these concepts with two different dose prescriptions have shown improved biochemical relapse-free survival applying an HDR-BT boost. However, survival rates were not reported to differ significantly $[15,16]$.

\section{Methods}

A group of 27 patients presenting with PSA progression during primary HT for local prostate cancer RT was identified among patients who were treated in the years 2000-2004 either using external-beam RT (EBRT; 70.2Gy; $\mathrm{n}=261$ ) or Ir-192 brachytherapy as a boost to EBRT (HDR-BT; 18Gy + 50.4Gy; $\mathrm{n}=71$ ). The indication for a specific treatment was generally based on the patient's and/or the referring urologist's preference. Only 7 patients received a short-term neoadjuvant HT $<6$ months. The median follow-up period after RT was 68 months.

A bone scan and abdominal computed tomography scan was required to exclude lymph node or skeletal metastases for high risk patients at the time of the initial diagnosis.

\section{Treatment}

The referring urologist decided about the indication for HT due to prognostic risk factors or to offer an immediate treatment before a later decision for a definitive curative method. As a consequence, several different agents have been used: luteinizing hormone-releasing hormone (LHRH) agonists in 10 cases (37\%), antiandrogens in 3 cases (11\%), a combination of LHRH agonists and antiandrogens in 5 cases (19\%) and an orchiectomy in 9 cases (33\%) in the group with PSA progression during initial HT.

An Ir-192 stepping source from an afterloader with a nominal activity of $370 \mathrm{GBq}$ was used for temporary HDR-BT. All patients received two fractions to deliver 18Gy to the prostate with 7 days between each fraction. Within three weeks after brachytherapy EBRT started. Three dimensional treatment plans were calculated using a four-field box technique with $15 \mathrm{MeV}$ photons and a multi-leaf collimator. The planning target volume was required to be enclosed by the $90 \%$ isodose relative to the International Commission on Radiation Units and Measurements reference point with a margin of $1.5 \mathrm{~cm}$ in the anterior/lateral and $1 \mathrm{~cm}$ in the craniocaudal and dorsal directions to the clinical target volume (prostate + /- seminal vesicles). The total median dose to the prostate in the reference point was $50.4 \mathrm{~Gy}$ at $1.8 \mathrm{~Gy}$ daily fractions. For EBRT without additional brachytherapy, the same technique was used up to a median dose of $70.2 \mathrm{~Gy}$ at $1.8 \mathrm{~Gy}$ fractions.

\section{Follow-up}

All patients had a pretreatment PSA measurement. PSA data since the initial diagnosis were collected retrospectively from the referring urologist, including the start of HT and PSA nadir value. The PSA levels were usually obtained every 3 or 4 months in the first 2 years and every 6 months thereafter. PSA failure (biochemical failure) was defined according to the RTOG-ASTRO Phoenix consensus [17]: (1) a rise by $2 \mathrm{ng} / \mathrm{ml}$ or more above the nadir PSA; (2) the date of failure determined "at call" (not backdated). An initiation of hormonal treatment after RT was additionally counted as biochemical failure.

Patients who died were censored at the time of death according to their status at that time. Disease specific mortality was defined as death from prostate cancer (patients who died with evidence of disease recurrence without an independent diagnosis responsible for the patient's death). Overall mortality was defined as death from any cause.

\section{Statistical analysis}

Statistical analysis was performed using the SPSS 19.0 (SPSS, Chicago, Ill), software. Contingency table analysis with the chi-square test was performed to compare treatment groups with respect to categorical variables. A t-test was used to compare patient age, follow-up periods and initial PSA values for patients in different subgroups.

Kaplan-Meier analysis was used to determine biochemical recurrence, disease specific and overall survival. Comparisons between groups were made using the log-rank test. Prognostic factors (T stage, Gleason score, pre-treatment PSA), radiotherapy technique, HT, duration of initial HT (dichotomized in $>6$ months = "longterm", and $\leq 6$ months = "short-term"), PSA progression during initial HT (PSA levels reaching a nadir and rising before beginning of RT) and PSA nadir before RT after initial HT (last PSA before beginning of RT considered for analysis) were tested for their significance in a univariate and multivariate Cox regression analysis $(\mathrm{p}<0.05$ is considered significant).

\section{Results}

Nearly half of the total patient group $(n=149)$ received an initial HT before RT with a curative intent, 19\% $(\mathrm{n}=62)$ for a time of more than 6 months (median 15 months, range 6-165 months). A PSA progression during initial HT was found in $8 \%$ (27 patients; $8 \%, n=22$, in the EBRT and 7\%, $\mathrm{n}=5$, in the HDR-BT subgroup).

Baseline patient characteristics for patients presenting with PSA progression during primary HT in contrast to 
other patients treated with one of the mentioned RT concepts in the years 2000-2004 are presented in Table 1. Patients with PSA progression during primary HT are clearly a selection of patients with adverse prognostic factors already at the time of the initial diagnosis.

Median biochemical recurrence free (BRFS), disease specific (DSS) and overall survival (OS) for patients with PSA progression during primary HT was found to be only 21,54 and 53 months, respectively, with a 6-year BRFS, DSS and OS of $19 \%, 41 \%$ and $26 \%$. There were no significant differences between different RT concepts (6year OS of $27 \%$ after EBRT and $20 \%$ after EBRT with HDR-BT). Metastases were diagnosed in 16 patients, with the initial location in bones in 11 patients and lymph nodes in 6 patients.

The outcome after EBRT and HDR-BT was far more favourable if all 332 patients were considered (6-year BRFS: $60 \%$ vs. $57 \%$; 6 -year DFS: $91 \%$ vs. $93 \%$; 6-year OS: $77 \%$ vs. $78 \%$; median values not reached). HDR-BT tended to be superior to EBRT alone for low risk patients considering BRFS (6-year BRFS: $94 \%$ vs. $72 \%$; $\mathrm{p}=0.08$ ), with excellent DFS rates (6-year DFS: $100 \%$ vs. 99\%). A lower PSA nadir after initial HT was found to be predictive for BRFS (6-year BRFS: $89 \%$ vs. $50 \%$ with a nadir $\leq 0.5 \mathrm{ng} / \mathrm{ml}$ vs. $>0.5 \mathrm{ng} / \mathrm{ml} ; \mathrm{p}=0.006)$. PSA progression during initial HT was a crucial adverse prognostic factor (6-year OS with vs. without PSA progression: $26 \%$ vs. $84 \%$; $\mathrm{p}<0.001$; 6-year DFS with vs. without PSA progression: $41 \%$ vs. $94 \%$; $\mathrm{p}<0.001$ ).
Only a few factors proved to have a significant impact in the multivariate analysis (Table 2). The established factors T stage $>2 \mathrm{a}$, Gleason score $>6$ and PSA $>10 \mathrm{ng} / \mathrm{ml}$ were all of prognostic relevance. Only Gleason score was found to be significantly relevant for (disease specific and overall) survival in our patient population. PSA progression and a nadir $>0.5 \mathrm{ng} / \mathrm{ml}$ during initial HT were both significant risk factors for biochemical recurrence. However, additionally to the Gleason score and patient age, only PSA progression during HT remained a significant predictor for survival in the multivariate analysis. Figures 1 and 2 well demonstrate the prognostic impact of PSA progression independently for the patient groups after EBRT alone or EBRT with an additional HDR-BT boost.

Patients with a shorter time to PSA progression after starting HT were found to have particularly low overall survival rates (Figure 3; 6-year overall survival of $0 \%$ vs. $57 \%$ with time to PSA progression $\leq 9$ months vs. $>9$ months). Median time to PSA progression was 9 months (in $41 \%<6$ months). Patients with a shorter time to PSA progression ( $\leq 9$ months) tended to have more frequently higher Gleason scores ( $62 \%$ vs. $36 \%$ Gleason score $>6$ ) and $\mathrm{T}$ stages $(85 \%$ vs. $64 \%>2 \mathrm{a})$.

Most of the patients with PSA progression during initial HT started RT with a PSA level $<10 \mathrm{ng} / \mathrm{ml}$ (63\%). OS of patients with PSA progression and a PSA level $<10 \mathrm{ng} / \mathrm{ml}$ vs. $\geq 10 \mathrm{ng} / \mathrm{ml}$ (last value before starting RT) did not differ significantly.

Table 1 Baseline patient characteristics

\begin{tabular}{|c|c|c|}
\hline & $\begin{array}{l}\text { PSA progression during } \\
\text { initial HT }(n=27)\end{array}$ & $\begin{array}{l}\text { Patient population without } \\
\text { PSA progression }(n=305)\end{array}$ \\
\hline $\begin{array}{l}\text { patient age/years median (range) } \\
\text { mean } \pm S D\end{array}$ & $74(45-81) 72 \pm 8$ & $71(52-84) 71 \pm 6$ \\
\hline $\begin{array}{l}\text { follow-up period/monthst median } \\
\text { (range) mean } \pm S D\end{array}$ & $48(11-113) 50 \pm 23$ & $69(2-115) 66 \pm 18$ \\
\hline T stage $>2$ a† & $74 \%$ & $25 \%$ \\
\hline Gleason score >6† & $48 \%$ & $19 \%$ \\
\hline $\begin{array}{l}\text { primary PSA /ng/mlt median (range) } \\
\text { mean } \pm \text { SD }\end{array}$ & $16(4-150) 31 \pm 37$ & $10(1-300) 16 \pm 25$ \\
\hline low risk patients ${ }^{*} \dagger$ & $7 \%$ & $37 \%$ \\
\hline intermediate risk patients ${ }^{* *} \dagger$ & $7 \%$ & $28 \%$ \\
\hline high risk patients ${ }^{* * *} \dagger$ & $85 \%$ & $35 \%$ \\
\hline initial HT (before RT) $\dagger$ & $100 \%$ & $40 \%$ \\
\hline initial HT >6monthst & $78 \%$ & $13 \%$ \\
\hline HDR-BT & $19 \%$ & $22 \%$ \\
\hline EBRT & $81 \%$ & $78 \%$ \\
\hline
\end{tabular}

" no risk factors: PSA $<10 \mathrm{ng} / \mathrm{ml}$; Gleason score $<7$; cT-stage $<2 \mathrm{~b}$.

** one risk factor: PSA $10-20 \mathrm{ng} / \mathrm{ml}$ or Gleason $\mathrm{score}=7$ or $\mathrm{CT}$-stage $=2 \mathrm{~b} / \mathrm{c}$.

*** two risk facors or PSA $>20 \mathrm{ng} / \mathrm{ml}$ or Gleason score $>7$ or cT-stage $>2 \mathrm{~b} / \mathrm{c}$.

tstatistically significant difference $(\mathrm{p}<0.01)$.

Abbreviations: $\mathrm{HDR}-\mathrm{BT}=$ high-dose rate brachytherapy; $\mathrm{EBRT}=$ external beam radiotherapy; $\mathrm{SD}=$ standard deviation; $\mathrm{PSA}=$ prostate-specific antigen; $\mathrm{HT}=$ hormonal therapy. 
Table 2 Significant factors in multivariate analysis

\begin{tabular}{|c|c|c|c|}
\hline & $\begin{array}{l}\text { Hazard } \\
\text { ratio }\end{array}$ & $\begin{array}{l}95 \% \text { confidence } \\
\text { interval }\end{array}$ & P-value \\
\hline \multicolumn{4}{|l|}{$\begin{array}{l}\text { Biochemical recurrence free } \\
\text { survival }\end{array}$} \\
\hline T stage $\leq 2 a$ & 1.7 & $1.1-2.5$ & 0.014 \\
\hline $\mathrm{PSA}<10 \mathrm{ng} / \mathrm{ml}$ & 1.9 & $1.2-2.8$ & 0.003 \\
\hline $\begin{array}{l}\text { no PSA progression vs. PSA pr. } \\
\text { with HT }\end{array}$ & 3.4 & $1.9-6.0$ & $<0.001$ \\
\hline no PSA progression vs. no HT & 1.5 & $1.2-21$ & 0.024 \\
\hline nadir $\leq 0.5$ vs. $>0.5$ after initial HT & 4.7 & $1.1-19$ & 0.034 \\
\hline \multicolumn{4}{|l|}{ Disease specific survival } \\
\hline Gleason score $\leq 6$ & 4.0 & $1.8-9.1$ & 0.001 \\
\hline $\begin{array}{l}\text { no HT vs. PSA progression with } \\
\text { HT }\end{array}$ & 23 & $7.3-72$ & $<0.001$ \\
\hline $\begin{array}{l}\text { no PSA progression vs. PSA pr. } \\
\text { with HT }\end{array}$ & 9.1 & $3.7-22$ & $<0.001$ \\
\hline \multicolumn{4}{|l|}{ Overall survival } \\
\hline age <70years & 2.6 & $1.5-4.4$ & $<0.001$ \\
\hline Gleason score $\leq 6$ & 2.2 & $1.4-3.7$ & 0.002 \\
\hline $\begin{array}{l}\text { no HT vs. PSA progression with } \\
\text { HT }\end{array}$ & 5.2 & 3.6-9.4 & $<0.001$ \\
\hline $\begin{array}{l}\text { no PSA progression vs. PSA pr. } \\
\text { with } \mathrm{HT}\end{array}$ & 7.2 & $3.9-14$ & $<0.001$ \\
\hline
\end{tabular}

Abbreviations: $\mathrm{PSA}=$ prostate-specific antigen; $\mathrm{HT}=$ hormonal therapy.

\section{Discussion}

Antiandrogen hormonal therapy is frequently combined with different RT methods. Treatment concepts are often based on the results of randomized trials, particularly for high risk patients receiving EBRT as a single

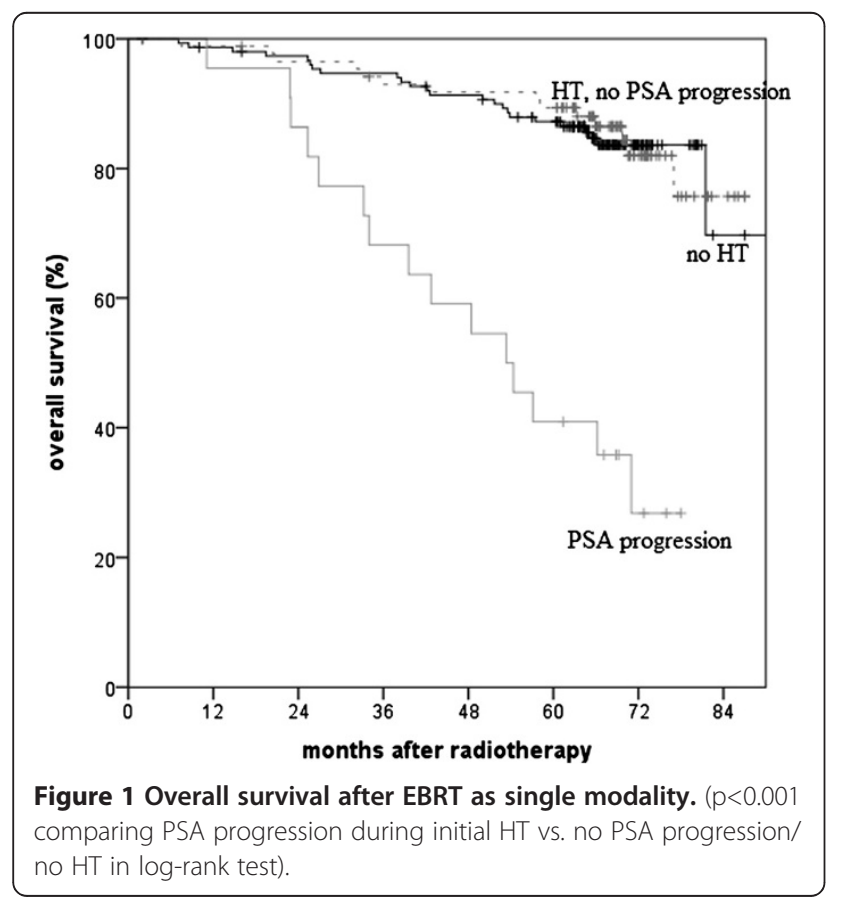

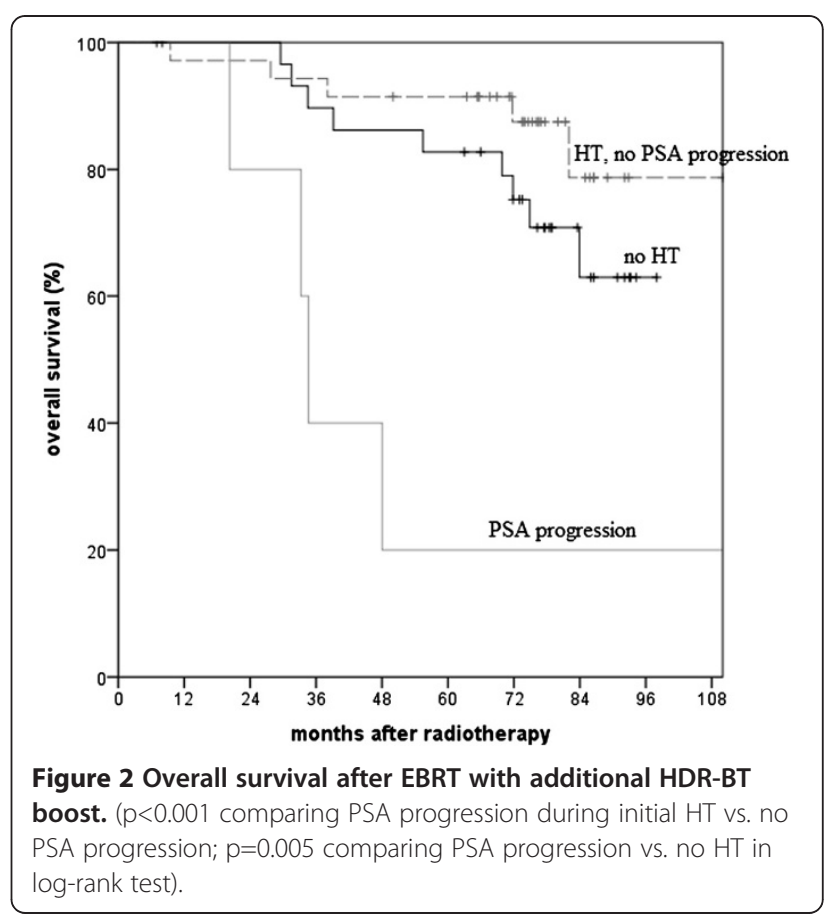

modality [9-11]. A longer duration of HT is usually favoured for high risk patients according to the results of prospective randomized trials, especially considering an adjuvant HT. Studies from the EORTC (European Organization for Research and Treatment of Cancer) and RTOG (Radiation Therapy Oncology Group) could demonstrate the survival benefit of the longer HT duration (three and two years) in comparison to a shorter duration (four and six months) [9,10]. A secondary

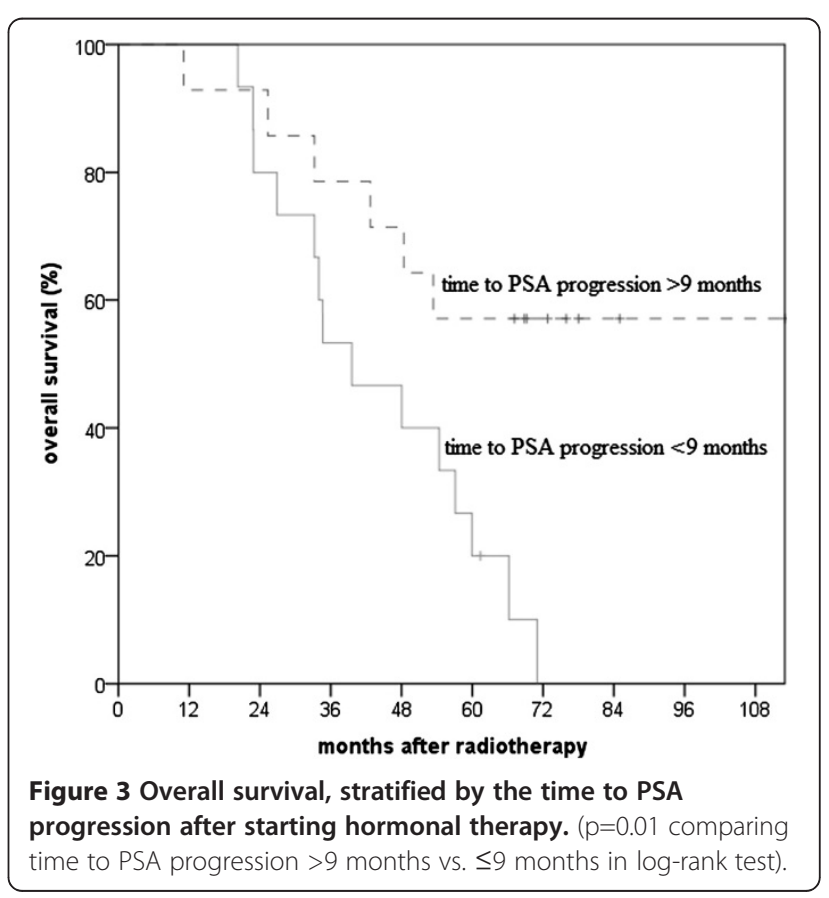


analysis of the RTOG 85-31 study reported improved survival for patients with HT treatment duration of more than five years (in comparison to one to five or less than one years) [18].

In contrast to HT, dose escalation studies did not show an overall survival benefit yet. A meta-analysis of randomized, controlled trials reported overall survival rates of $86 \%$ for both high-dose and low-dose radiotherapy [19], so that a relatively low total dose of 70.2Gy for patients treated with EBRT alone in this study can not explain a prognostic disadvantage in this respect. Accordingly - corresponding to the results of this study randomized studies comparing a HDR-BT boost to EBRT in comparison to EBRT alone did not result in an overall survival benefit $[15,16]$.

Even six months of short-term neoadjuvant HT proved to be associated with increased overall survival in locally advanced prostate cancer (TROG, Trans-Tasman Radiation Oncology Group, 96.01 trial) [20]. A Canadian multi-center trial comparing three months versus eight months of neoadjuvant HT in patients with localized prostate cancer has shown a significant overall survival benefit for high risk patients [18]. However, a recently published analysis of this trial found the biochemical response to neoadjuvant HT to be the critical determinant of benefit in the setting of combined therapy. Multivariate analysis identified post-hormone PSA (PSA nadir before beginning of RT), Gleason score, initial PSA and Tstage, not HT duration, as independent predictors of biochemical disease free survival [21]. The PSA level after 7 months of HT has also been found to be a strong independent predictor of survival in new metastatic prostate cancer in a Southwest Oncology Group (SWOG) trial [22]. These results are in accordance with the results of our study, demonstrating the independent impact of prognostic factors and post-hormone PSA nadir on biochemical disease free survival. An additional independent prognostic risk factor was found in our patient population, namely a PSA progression during initial HT.

With a significant impact for biochemical recurrence free survival in multivariate analysis, the PSA nadir could probably become significant in multivariate analysis for disease and overall survival after a longer follow-up interval. Patients with PSA progression during initial HT appear to be a selection with extremely aggressive prostate cancer. These cancers have a considerable impact on short term survival rates in contrast to usually expected high disease specific survival rates after definitive curative RT (99\% 5-year DSS for patients without initial HT in this study).

Two possible reasons can be attributed to this unfavourable prognosis. First, these tumours consist of a considerable amount of preselected aggressive cells that are resistant to antiandrogen therapy and apparently simultaneously resistant to radiation. Secondly, these tumours have a high metastatic potential, leading to the imminent threat to the patient's life. A particularly unfavourable prognosis was found for patients with a PSA progression after only a few months of HT, indicating a fast resistance to treatment.

A comparable study of patients receiving irradiation for localized prostate cancer in case of a PSA progression after initial HT is presently not available in the literature. The survival rates that were found in our study after RT are comparable to studies evaluating the outcome of androgen independent prostate cancer without any recorded local treatment $[23,24]$. Svatek et al. [24] reported a median disease specific and overall survival of 54 months and 51 months, respectively, for a population of 129 untreated consecutive patients with androgen independent prostate cancer. These data are well comparable to a median disease specific and overall survival of 54 months and 53 months in our study, so that a benefit of a local RT is not clear in this patient population. The decision for a local RT should be made considering this prognosis.

This is a retrospective analysis in a consecutively treated patient population, so that limitations exist due to a variety of underlying confounding factors. The generated hypothesis should be evaluated in other independent data sets. Imaging studies, like computed tomography of the abdomen, bone scan or choline-PET [2] might be useful not only at the time of the initial diagnosis but also before the decision for local RT even with smaller PSA levels, taking into account the high metastatic potential.

\section{Conclusions}

PSA progression during initial antiandrogen hormonal therapy was found to be independently associated with an unfavorable prognosis after local radiotherapy for prostate cancer. This outcome needs to be considered in the decision process before local prostate radiotherapy. However, results from other centres are needed to validate our findings.

\section{Competing interests}

The authors declare that they have no competing interests.

\section{Authors' contributions}

MP, MJE have made substantial contributions to conception and design; MP, MDP, RH, VD, JK, MJE have made substantial contributions to acquisition of data; MP, MDP, RH, DP, AH, MJE to analysis and interpretation of data. MP has been involved in drafting the manuscript. MDP, RH, VD, JK, DP, AH, MJE revised it critically for important intellectual content. All authors have given final approval of the version to be published.

\section{Acknowledgements}

We would like to thank the staff who took care of our patients' needs, and who were involved in gathering, documenting, verifying, forwarding, and processing the clinical data. 


\section{Author details}

'Department of Radiation Oncology, RWTH Aachen University,

Pauwelsstrasse 30, 52072 Aachen, Germany. ${ }^{2}$ Department of Urology, RWTH

Aachen University, Pauwelsstrasse 30, 52072 Aachen, Germany.

Received: 22 August 2012 Accepted: 8 December 2012

Published: 10 December 2012

\section{References}

1. Heidenreich A, Bellmunt J, Bolla M, Joniau S, Mason M, Matveev V, Mottet N, Schmid HP, van der Kwast T, Wiegel T, Zattoni F: EAU guidelines on prostate cancer, part 1: screening, diagnosis and treatment of clinically localised disease. Eur Urol 2011, 59:61-71.

2. Pinkawa M: External beam radiotherapy for prostate cancer. Panminerva Med 2010, 52:195-207.

3. Pinkawa M, Piroth DM, Holy R, Fischedick K, Schaar S, Borchers $H$, Heidenreich A, Eble MJ: Prostate-specific antigen kinetics following external-beam radiotherapy and temporary (Ir-192) or permanent (I-125) brachytherapy for prostate cancer. Radiother Oncol 2010, 96:25-29.

4. Grimm P, Billiet I, Bostwick D, Dicker AP, Frank S, Immerzeel J, Keyes M Kupelian P, Lee WR, Machtens S, Mayadev J, Moran BJ, Merrick G, Millar J, Roach M, Stock R, Shinohara K, Scholz M, Weber E, Zietman A, Zelefsky M, Wong J, Wentworth S, Vera R, Langley S: Comparative analysis of prostatespecific antigen free survival outcomes for patients with low, intermediate and high risk prostate cancer treatment by radical therapy: results from the prostate cancer results study group. BJU Int 2012, 109(Suppl.1):22-29.

5. Gill S, Thomas J, Fox C, Kron T, Rolfo A, Leahy M, Chander S, Williams S, Tai $\mathrm{KH}$, Duchesne GM, Foroudi F: Acute toxicity in prostate cancer patients treated with and without image-guided radiotherapy. Radiat Oncol 2011, 6:145.

6. Prada PJ, Mendez L, Fernández J, González H, Jiménez I, Arrojo E: Longterm biochemical results after high-dose-rate intensity modulated brachytherapy with external beam radiotherapy for high risk prostate cancer. Radiat Oncol 2012, 7:31.

7. Pinkawa M, Piroth MD, Holy R, Klotz J, Djukic V, Corral NE, Caffaro M, Winz $\mathrm{OH}$, Krohn T, Mottaghy FM, Eble MJ: Dose-escalation using intensitymodulated radiotherapy for prostate cancer - evaluation of quality of life with and without (18)F-choline PET-CT detected simultaneous integrated boost. Radiat Oncol 2012, 7:14

8. Bolla M, van Tienhoven G, Warde P, Dubois JB, Mirimanoff RO, Storme G, Bernier J, Kuten A, Sternberg C, Billiet I, Torecilla JL, Pfeffer R, Cutajar CL, Van der Kwast T, Collette L: External irradiation with or without long-term androgen suppression for prostate cancer with high metastatic risk: 10 year results of an EORTC randomised study. Lancet Oncol 2010, 11:1066-1073.

9. Bolla M, de Reijke TM, van Tienhoven G, Van den Bergh AC, Oddens J, Poortmans PM, Gez E, Kil P, Akdas A, Soete G, Kariakine O, van der SteenBanasik EM, Musat E, Piérart M, Mauer ME, Collette L: Duration of androgen suppression in the treatment of prostate cancer. N Engl J Med 2009, 360:2516-2527.

10. Hanks GE, Pajak TF, Porter A, Grignon D, Brereton H, Venkatesan V, Horwitz EM, Lawton C, Rosenthal SA, Sandler HM, Shipley WU: Phase III trial of long-term adjuvant androgen deprivation after neoadjuvant hormonal cytoreduction and radiotherapy in locally advanced carcinoma of the prostate: the Radiation Therapy Oncology Group Protocol 92-02. J Clin Oncol 2003, 21:3972-3978.

11. Pilepich MV, Winter K, Lawton CA, Krisch RE, Wolkov HB, Movsas B, Hug EB, Asbell SO, Grignon D: Androgen suppression adjuvant to definitive radiotherapy in prostate carcinoma-long-term results of phase III RTOG 85-31. Int J Radiat Oncol Biol Phys 2005, 61:1285-1290.

12. Iversen P, McLeod DG, See WA, Morris T, Armstrong J, Wirth MP: Antiandrogen monotherapy in patients with localized or locally advanced prostate cancer: final results from the bicalutamide early prostate cancer programme at a median follow-up of 9.7 years. BJU Int 2010, 105:1074-1081.

13. Kucway R, Vicini F, Huang R, Stromberg J, Gonzalez J, Martinez A: Prostate volume reduction with androgen deprivation therapy before interstitial brachytherapy. J Urol 2002, 167:2443-2447.

14. Crook J, Ludgate C, Malone S, Perry G, Eapen L, Bowen J, Robertson S, Lockwood G: Final report of a multicenter Canadian phase III randomized trial of 3 vs. 8 months neoadjuvant androgen deprivation before conventional dose radiotherapy for clinically localized prostate cancer. Int J Radiat Oncol Biol Phys 2009, 73:327-333.

15. Sathya JR, Davis IR, Julian JA, Guo Q, Daya D, Dayes IS, Lukka HR, Levine M: Randomized trial comparing Iridium implant plus external-beam radiotherapy with external-beam radiotherapy alone in node-negative locally advanced cancer of the prostate. J Clin Oncol 2005, 23:1192-1199.

16. Hoskin PJ, Rojas AM, Bownes PJ, Lowe GJ, Ostler PJ, Bryant L: Randomised trial of external beam radiotherapy alone or combined with high-doserate brachytherapy boost for localised prostate cancer. Radiother Oncol 2012, 103:217-222.

17. Roach M III, Hanks G, Thames H, Schellhammer P, Shipley WU, Sokol GH, Sandler $\mathrm{H}$ : Defining biochemical failure follwing radiotherapy with or without hormonal therapy in men with clinically localized prostate cancer: recommendations of the RTOG-ASTRO Phoenix consensus conference. Int J Radiat Oncol Biol Phys 2006, 65:965-974.

18. Souhami L, Bae K, Pilepich M, Sandler H: Impact of the duration of adjuvant hormonal therapy in patients with locally advanced prostate cancer: a secondary analysis of RTOG 85-31. J Clin Oncol 2009, 27:2137-2143.

19. Viani GA, Stefano EJ, Alfonso SL: Higher-than-conventional radiation doses in localized prostate cancer treatment. Int J Radiat Oncol Biol Phys 2009, 74:1405-1418.

20. Denham JW, Steigler A, Lamb DS, Joseph D, Turner S, Matthews J, Atkinson C, North J, Christie D, Spry NA, Tai KH, Wynne C, D'Este C: Short-term neoadjuvant androgen deprivation and radiotherapy for locally advanced prostate cancer: 10-year data from the TROG 96.01 randomised trial. Lancet Oncol 2011, 12:451-459.

21. Alexander AA, Crook J, Jones S, Malone S, Bowen J, Truong P, Pai H, Ludgate $C$ : Is biochemical response more important than duration of neoadjuvant hormone therapy before radiotherapy for clinically localized prostate cancer? An analysis of the 3-versus 8-month randomized trial. Int J Radiat Oncol Biol Phys 2010, 76:23-30.

22. Hussain M, Tangen CM, Higano C, Schelhammer PF, Faulkner J, Crawford ED, Wilding G, Akdas A, Small EJ, Donnelly B, MacVicar G, Raghavan D: Absolute prostate-specific antigen value after androgen deprivation is a strong independent predictor of survival in new metastatic prostate cancer: data from Southwest Oncology Group Trial (INT-0162). J Clin Oncol 2006, 24:3984-3990.

23. Oefelein MG, Agarwal PK, Resnick MI: Survival of patients with hormone refractory prostate cancer in the prostate specific antigen era. J Urol 2004, 171:1525-1528.

24. Svatek R, Karakiewicz PI, Shulman M, Karam J, Perrotte P, Benaim E: Pretreatment nomogram for disease-specific survival of patients with chemotherapy-naive androgen independent prostate cancer. Eur Urol 2006, 49:666-674.

doi:10.1186/1748-717X-7-209

Cite this article as: Pinkawa et al:: Local prostate cancer radiotherapy after prostate-specific antigen progression during primary hormonal therapy. Radiation Oncology 2012 7:209.

\section{Submit your next manuscript to BioMed Central and take full advantage of:}

- Convenient online submission

- Thorough peer review

- No space constraints or color figure charges

- Immediate publication on acceptance

- Inclusion in PubMed, CAS, Scopus and Google Scholar

- Research which is freely available for redistribution 